\title{
Perceptions of Clinical Decision-Making Skills among Saudi Nursing Students: A Comparative Study
}

\author{
Reem Nassar AL-Dossary ${ }^{1}$ Sherien Ragab Abdelsamed Dorgham ${ }^{1} \quad$ Jestoni Dulva Maniago ${ }^{2}$ \\ ${ }^{1}$ Department of Nursing Education, College of Nursing, Imam \\ Abdulrahman Bin Faisal University, Dammam, Saudi Arabia \\ 2Department of Nursing, College of Applied Medical Sciences, \\ Majmaah University, Saudi Arabia

\begin{abstract}
Address for correspondence Jestoni Dulva Maniago, DNSc, Majmaah University, Al Majmaah, Ar Riyadh 11952, Saudi Arabia (e-mail: je.maniago@mu.edu.sa).
\end{abstract} \\ Department of Nursing, College of Applied Medical Sciences,
}

J Health Allied Sci NU 2019;9:91-97

\begin{abstract}
Keywords

- baccalaureate

- bridging

- clinical simulation

- nursing education

- cross-sectional

- quality patient care
\end{abstract}

Introduction As complexities in healthcare and medical technology increase, nursing students and newly graduated nurses may often feel less confident and have fewer skills in decision-making than experienced nurses.

Objective The main purpose of this article is to explore nurses' perceptions of their clinical decision-making skills.

Materials and Methods A comparative, cross-sectional design was used to conduct a study at a college of nursing in the Eastern Province of Saudi Arabia. The sample consisted of students ( $n=139)$ enrolled in bridging $(n=72)$ and undergraduate (basic; $n=67$ ) programs.

Results Highly statistically significant differences were revealed between students in the bridging program and those in the undergraduate program. Those in the bridging program showed higher mean and median values than did undergraduate students, demonstrating better decision-making skills.

Conclusion Students in the bridging program have better decision-making skills compared with students in the baccalaureate program.

\section{Introduction}

Increasing complexity in healthcare settings creates challenges for clinical teaching owing to the demanding working environment, ever-increasing patient acuity, and advanced technologies. ${ }^{1}$ Because of this complexity, it is necessary for nurses to depend on clinical decision-making that is guided by the most current research and evidence-based guidelines to maintain patient safety and deliver high-quality care..-4 According to Tomlinson, ${ }^{5}$ poor clinical decision-making practice is responsible for more than half of clinical errors. It is imperative, then, that teaching of decision-making skills be a fundamental component of nursing education. ${ }^{6}$ Decision-making is a vital tool that nursing students should acquire to carry out their daily complex tasks. ${ }^{7}$ Nursing faculty face daily challenges in helping to graduate competent nurses to meet the demand in this era of high-acuity patients.

Clinical decision-making research started as early as $1966 .{ }^{8}$ Readers may need to be aware that over the past five decades "terminological chaos" has reigned in the nursing literature regarding the term "clinical decision-making." The following terms have been used interchangeably, although they are different concepts or part of clinical decision-making: "clinical judgment," "clinical reasoning," "problem solving," "critical thinking," and "clinical inference." The definition developed by Tiffen et $\mathrm{al}^{9}$ serves to clarify the term "clinical decision-making" in the context of this paper: "Clinical decision making is a contextual, continuous, and evolving process, where data are gathered, interpreted, and evaluated in order to select an evidence-based choice of action."

Though Jahanpour et $\mathrm{al}^{6}$ have stated that clinical decision-making skills can be learned, the nursing literature illustrates that nursing students and new graduate nurses lack these skills., ${ }^{3,10}$ To remedy this situation, nursing educators need to incorporate clinical decision-making skills into the nursing curriculum. Students should be engaged at all educational levels with clinical scenarios that will allow them to practice decision-making skills. Nursing educators
Copyright @2019 Nitte University (Deemed to be University)
License terms

(요 (1) $\Theta \circledast$ 
should plan curricula that include clinical methods and pedagogy that will prepare nurses for the ever-evolving clinical environment. ${ }^{4}$ Further, clinical exposure also provides nursing students with opportunities in developing decision-making skills. ${ }^{11}$ The function of nursing educators is to prepare nursing students to function successfully in ever-changing healthcare systems. Students must be able to demonstrate their decision-making abilities with all patient scenarios or conditions. ${ }^{8}$ In fact, it is very important that nurse educators understand that poor decisions are costly; thus, nursing students must learn and demonstrate effective decisions. Thus, the purpose of the study is to explore the perceptions of the clinical decision-making skills of students enrolled in both bridging and baccalaureate nursing programs.

\section{Introduction}

In Saudi Arabia, although numerous challenges face the nursing profession, like many countries worldwide, it has progressed markedly in such aspects as education and clinical practice. ${ }^{8}$ A great many of the nurses have traditionally been "diploma nurses." That is, these nurses, either after high school or after college, have gone through a basic program of 2 to 3 years plus a 6-month internship, which was designed to prepare students to become the equivalent of licensed practical nurses in the United States. Once students receive a diploma, they can take the exam for obtaining certification as a practical nurse. To become a Bachelor of Science in Nursing (BSN), the student nurse should have 4 years of training, a baccalaureate degree, and a year of internship.

Like the rest of the world, the Kingdom of Saudi Arabia has a nursing shortage, which poses challenges to its healthcare system. ${ }^{3}$ As mentioned earlier, healthcare demands are also becoming more difficult because of increased patient acuity and more complex technologies. ${ }^{12}$ In response to these various challenges in nursing and with the intent to improve nursing education, the Kingdom of Saudi Arabia transferred all nursing colleges and health institutes from the Ministry of Health to the Ministry of Higher Education during 2008. In 2010, the Ministry of Health implemented the recommendation of the World Health Organization that emphasizes the baccalaureate degree as the minimum requirement for entry into the nursing profession. ${ }^{13}$ As of 2011 , more than 10,000 Saudi nurses were still diploma graduates. A report from the Institute of Medicine ${ }^{14}$ established the aim that by 2020, the percentage of nurses with baccalaureate degrees would be increased to $80 \%$. Better-educated nurses would be more capable of assuming numerous roles in clinical practice, such as leadership, teaching, and research. Such a competent nursing workforce would also be better equipped to meet the demands of the rapid changes in healthcare.

In yet another effort to meet the international standards for the nursing profession, the government of Saudi Arabia has introduced its 2030 Vision for improving the healthcare in the nation. ${ }^{8}$ To improve the quality of nursing services provided by Saudi healthcare organizations, the Ministry of Health and the Saudi Council for Health Specialties have recommended that a baccalaureate degree be the minimum requirement for entry level nursing practice. ${ }^{15}$ To meet these challenges and recommendations and to enable as many practicing nurses as possible to meet the newly established requirement, Saudi Arabian universities have developed nursing bridging programs, or what is known as Registered Nurse to Bachelor of Science in Nursing (RN-to-BSN).

By 2012, the College of Nursing at Imam Abdurrahman Bin Faisal University had opened such a program to diploma nurses in Saudi Arabia. These programs are designed for registered diploma nurses who desire to upgrade their qualifications by getting a baccalaureate degree (RN-to-BSN). The aim is to prepare competent nurses who will be able to meet the national demand and to improve the quality of patient care. ${ }^{16}$ Compared to the baccalaureate nursing program that offers 5 years of study including 1 year of clinical internship, the bridging program's duration is shorter ( $\sim 3$ years, including 6 months of clinical training). These programs provide diploma nurses with the knowledge and skills to improve the quality of health services provided to improve the nursing profession in Saudi Arabia. They are similar to the undergraduate nursing program but shorter in length as they are intended to complete the education and training that diploma nurses already have. Despite the difference in the duration of study, both programs were taught on clinical decision-making. This skill was integrated in all professional and clinical courses in which all students are required to complete the prescribed number of hours.

According to Kriston et al, ${ }^{17}$ the treatment of decision-making in the nursing research is often disjointed and hence somewhat disconnected. Therefore, it is crucial that nurse educators gain a better understanding of students' perceptions of their clinical decision-making skills for more effective teaching of this skill. ${ }^{18}$ Knowing nursing students' perceptions of their clinical decision-making skills, for example, can provide sufficient information to help nurse educators develop and/or revise curricular activities in the clinical setting to promote and support decision-making skills. Comparing undergraduate and bridging nursing students' perceptions may provide knowledge of any significant differences between the two programs. The perceptions of undergraduate and bridging nursing students must be understood to ensure that their learning needs are being met through the nursing curriculum. Since the inception of the RN-to-BSN program, examining and comparing bridging and baccalaureate nursing students' perceptions of decision-making has not been studied in Saudi Arabia. However, it is important to understand nurses' clinical decision-making to ensure that sound decision-making skills are being taught to nursing students in both programs, allowing them to deal with the daily challenges they will face in healthcare settings.

\section{Materials and Methods}

\section{Research Design, Setting, and Population}

An exploratory, comparative, cross-sectional study design was used to explore the perceptions of the clinical decision-making skills of Saudi students enrolled in both bridging and baccalaureate nursing programs. The study was 
conducted at a college of nursing in the Eastern Province of Saudi Arabia. It employed a convenience sample of 139 Saudi nurse students enrolled in bridging $(n=72)$ and baccalaureate $(n=67)$ nursing programs.

The researchers were meticulous in finalizing the inclusion and exclusion criteria for target population to prevent selection bias and sample contamination. Fourth-year undergraduate nurse students enrolled in baccalaureate nursing programs and second-year bridging nurse students enrolled in bridging nursing programs were chosen to participate in the study. These students have studied the same courses and are at equivalent levels in their respective programs. Students from the first 3 years of the baccalaureate nursing program were excluded from the study, as well as first-year students in the bridging programs.

\section{Instrument}

The Jenkins' Clinical Decision Making in Nursing Scale (CDMNS), ${ }^{19}$ a self-administered questionnaire, was used to collect data; the tool was adopted with permission. The questionnaire is composed of 40 items allocated to four subscales: search for alternatives and options scale, canvassing of objectives and values scale, evaluation and reevaluation of consequences scale, and search for information and unbiased assimilation of new information scale.

The dependent variable, clinical decision-making, was measured using the CDMNS. ${ }^{19}$ Examples from the CDMNS subscales are as follows: search for alternatives and options ("If the clinical decision is vital and there is time, I conduct a thorough search for alternatives"), canvassing of objectives and values ("When a person is ill, his or her cultural values and beliefs are secondary to the implementation of health services"), evaluation and reevaluation of consequences ("I do not always take time to examine all the possible consequences of a decision I must make"), and search for information and unbiased assimilation of new information ("Looking for new information in making a decision is more trouble than it is worth"). To prevent bias and contamination of data, the researchers included open-ended questions at the end of each subscale. In this way, the researchers were able to explore and gain a better perspective of the scope of their clinical decision-making in nursing.

This instrument uses a five-point Likert scale ranging from "always" to "never" to elicit nursing students' perceptions of their own clinical decision-making skills in clinical practice. The CDMNS instrument provides an overall score for each of the four subscales' scores, which are composed of 10 items each, and the possible scores range from 10 to 50 for each subscale. The CDMNS instrument also provides one overall score for total clinical decision-making. The possible scores range from 40 to 200 . The higher scores indicate higher perceived skills in decision-making and the lower scores indicate lower perceived decision-making skills. It takes $\sim 20$ minutes to complete the questionnaire.

The CDMNS has an established reliability with a Cronbach's $\alpha$ of $0.836,{ }^{20}$ which indicates a good reliability. The CDMNS instrument in this study had a Cronbach's $\alpha$ of 0.836 ( $n=139$ ), with subscales ranging from 0.573 to 0.681 . This indicates a good reliability for the CDMNS instrument and its subscales.

\section{Ethical Considerations}

The Human Studies Review Board of Imam Abdulrahman Bin Faisal University approved this study. All potential participants were informed of the purpose of the study and were given the choice not to participate. Written informed consent was secured prior to data collection. Confidentiality was a priority in this study, so no personal identifications were requested.

\section{Data Collection and Analysis}

Research assistants recruited participants face-to-face at the College of Nursing and then collected data by means of a paper-and-pencil survey. The researchers conducted a pilot study $(n=25)$ from November 2018 to December 2018 to determine the level of understanding and the length of time participants might need to complete the questionnaire. The pilot group participants from bridging and baccalaureate programs had the same characteristics as those who took part in the study sample $(n=139)$. The duration of actual data collection for 139 participants lasted for 4 months (January 2019 to May 2019) just before the end of the academic year.

Descriptive statistics were used to analyze demographic data. Inferential statistics (i.e., Student's $t$-tests) were performed to evaluate any statistically significant differences in clinical decision-making subscales between the study groups (i.e., bridging and undergraduate students). In addition, $t$-tests were conducted to assess whether there were significant mean differences in the overall score for the complete clinical decision-making scale. Data were analyzed using the Statistical Package for the Social Sciences Version 20.0.

\section{Results}

- Table 1 illustrates the distribution of students in the baccalaureate and bridging nursing programs according to gender and marital status. More than two-thirds of students in the undergraduate program are females, whereas just a little over half in the bridging program are females. There is no statistically significant difference between the two groups regarding gender $(p>0.05)$. In relation to marital status, there is a statistically significant difference between the two groups. The majority of students in the bridging program are married compared with students in the undergraduate program, of whom less than one-third are married.

- Table 2 demonstrates the distribution of students in the baccalaureate and bridging nursing programs according to their average study hours per day. The highest percentage of students in both baccalaureate and bridging nursing programs reported that they studied, on average, 2 to 4 hours/day. Although the proportion of students with an average of study hours greater than 7 hours/day is higher for the bridging group compared with the baccalaureate, the 
Table 1 Distribution of students in baccalaureate and bridging nursing programs related to gender and marital status

\begin{tabular}{|c|c|c|c|c|c|c|c|c|c|}
\hline & \multicolumn{2}{|c|}{ Sex } & \multirow{2}{*}{$\begin{array}{l}\text { Chi-squared } \\
\text { test }\end{array}$} & \multirow[t]{2}{*}{$p$-Value } & \multicolumn{3}{|c|}{ Marital status } & \multirow{2}{*}{$\begin{array}{l}\text { Chi-squared } \\
\text { test }\end{array}$} & \multirow[t]{2}{*}{$p$-Value } \\
\hline & $\begin{array}{l}\text { Male } \\
(\%)\end{array}$ & $\begin{array}{l}\text { Female } \\
(\%)\end{array}$ & & & Single (\%) & Married (\%) & Divorced (\%) & & \\
\hline $\begin{array}{l}\text { Under- } \\
\text { graduate } \\
\text { program }\end{array}$ & 33.3 & 66.7 & \multirow[t]{2}{*}{2.00} & \multirow[t]{2}{*}{$>0.05$} & 68.3 & 28.3 & 3.3 & \multirow[t]{2}{*}{24.4} & \multirow[t]{2}{*}{$<0.005$} \\
\hline $\begin{array}{l}\text { Bridging } \\
\text { program }\end{array}$ & 45.6 & 54.4 & & & 26.5 & 72.1 & 1.5 & & \\
\hline
\end{tabular}

Table 2 Distribution of students' average study hours per day in undergraduate and bridging nursing programs

\begin{tabular}{|c|c|c|c|c|c|c|c|}
\hline \multirow[t]{2}{*}{ Programs } & \multicolumn{4}{|c|}{ Studying hours per day average } & \multirow[t]{2}{*}{ Total (\%) } & \multirow[t]{2}{*}{ Chi-squared test } & \multirow[t]{2}{*}{$p$-Value } \\
\hline & $\begin{array}{l}\text { Less than } \\
2 \mathrm{~h}(\%)\end{array}$ & $2-4 \mathrm{~h}(\%)$ & $5-6$ h (\%) & $\begin{array}{l}\text { More than } 7 \mathrm{~h} \\
(\%)\end{array}$ & & & \\
\hline Undergraduate program & 21.7 & 48.3 & 21.7 & 8.3 & 100 & \multirow[t]{2}{*}{7.23} & \multirow[t]{2}{*}{$>0.05$} \\
\hline Bridging program & 20.0 & 32.3 & 24.6 & 23.1 & 100 & & \\
\hline Total & 20.8 & 40.0 & 23.2 & 16.0 & 100 & & \\
\hline
\end{tabular}

difference in general between the two programs' distributions was not statistically significant.

- Table 3 shows the distribution of students in the baccalaureate and bridging nursing programs related to hours spent in class per week. There is a statistically significant difference between the distributions of the two programs. While the proportion of baccalaureate program spending 21 to 25 hours is $16.9 \%$, it is $0 \%$ for bridging program. On the contrary, $44.1 \%$ of bridging students spend more than 26 hours in class per week compared with $33.9 \%$ for baccalaureate students.

- Table 4 shows the distribution of students in baccalaureate and bridging nursing programs related to hours spent at clinical rotations per week. There is an almost statistically significant difference between the distributions of the two programs. Whereas the proportion of baccalaureate students spending 16 to 20 hours in clinical rotations per week is almost 15 percentage points higher than for bridging students, nearly a quarter of bridging students spend more than 26 hours in clinical rotations per week compared with less than $10 \%$ for baccalaureate students.

- Table 5 shows the comparison between baccalaureate and bridging nursing students in their perceived clinical decision-making skills. It can be noticed that for all subscales and total CDMNS scale, the students in the bridging program have higher values for the mean than baccalaureate students. The differences are statistically significant $(p<0.05)$ for all subscales and the total CDMNS scale. Higher means indicate, in general, higher scores for the perceived clinical decision-making skills of bridging students compared with baccalaureate nursing students.

\section{Discussion}

Nurses who are competent decision-makers in responding to and meeting patients' needs are particularly needed in today's vigorous and ambiguous healthcare context. It was partly in response to this need that the Saudi government instituted a bridging program whereby current nurses may obtain a baccalaureate degree. The current study constitutes a start in examining this program by comparing the perceived decision-making skills of the students in this program to those of students in the baccalaureate degree program.

Overall, the students in the bridging program demonstrate higher scores, and hence higher means, than the students in the baccalaureate program. Some reasons for this can be deduced from the results. First, the average of study hours per day was found to be higher for bridging students compared with students in the baccalaureate program. This result may be owing to the maturity of the bridging students, who are on average older than the baccalaureate students. Most of bridging students are married, which entails higher sense of responsibility and motivation to complete the program. Furthermore, the bridging program is optional: students choose to enter the program to improve their education and give better economic opportunity for their families; therefore, they have strong motivation to work hard and receive their degrees. The bachelor's nursing programs are structured with the knowledge that diploma nurses are already trained in these areas and are seeking more advanced knowledge and greater autonomy.

Study results also revealed a statistically significant difference between the distributions of the two groups in relation to the number of hours spent in class per week. Students enrolled in the bridging program spent more hours in class per week than did those in the baccalaureate program. These results may be attributed to the fact that the bridging program is more condensed; it is 2 years in length in terms of class work, as compared with the baccalaureate program, which is 4 years long. These results are consistent with those of Bashatah and Alkorashy, ${ }^{15}$ who reported that although the bridging nursing programs are shorter in length of time, compared with the baccalaureate nursing programs, they 
Table 3 Distribution of students in baccalaureate and bridging nursing programs related to hours spent in class per week

\begin{tabular}{|c|c|c|c|c|c|c|c|c|}
\hline \multirow[t]{2}{*}{ Programs } & \multicolumn{5}{|c|}{ Hours spent in class per week } & \multirow[t]{2}{*}{ Total (\%) } & \multirow{2}{*}{$\begin{array}{l}\text { Chi-squared } \\
\text { test }\end{array}$} & \multirow[t]{2}{*}{$p$-Value } \\
\hline & $\begin{array}{l}1-10 \\
h / w k(\%)\end{array}$ & $\begin{array}{l}\text { 11-15 } \\
\text { h/wk (\%) }\end{array}$ & $\begin{array}{l}16-20 \\
\text { h/wk (\%) }\end{array}$ & $\begin{array}{l}21-25 \\
\text { h/wk (\%) }\end{array}$ & $\begin{array}{l}\text { More than } \\
26 \text { h/wk (\%) }\end{array}$ & & & \\
\hline $\begin{array}{l}\text { Undergraduate } \\
\text { program }\end{array}$ & 8.5 & 8.5 & 32.2 & 16.9 & 33.9 & 100 & \multirow[t]{2}{*}{13.36} & \multirow[t]{2}{*}{$<0.05$} \\
\hline Bridging program & 11.8 & 13.2 & 30.9 & 0 & 44.1 & 100 & & \\
\hline Total & 10.2 & 11.0 & 31.5 & 7.9 & 39.4 & 100 & & \\
\hline
\end{tabular}

Table 4 Distribution of students in baccalaureate and bridging nursing programs according to hours spent at clinical rotations per week

\begin{tabular}{|c|c|c|c|c|c|c|c|c|}
\hline \multirow[t]{2}{*}{ Programs } & \multicolumn{5}{|c|}{ Hours spent at clinical rotations per week } & \multirow[t]{2}{*}{ Total (\%) } & \multirow[t]{2}{*}{ Chi-squared test } & \multirow[t]{2}{*}{$p$-Value } \\
\hline & $\begin{array}{l}1-10 \mathrm{~h} / \\
\text { wk (\%) }\end{array}$ & $\begin{array}{l}11-15 \mathrm{~h} / \\
\text { wk (\%) }\end{array}$ & $\begin{array}{l}16-20 \mathrm{~h} / \\
\text { wk (\%) }\end{array}$ & $\begin{array}{l}21-25 \text { h/ } \\
\text { wk (\%) }\end{array}$ & $\begin{array}{l}\text { More } \\
\text { than } 26 \\
\text { h/wk (\%) }\end{array}$ & & & \\
\hline Undergraduate program & 5.0 & 18.3 & 48.3 & 21.7 & 6.7 & 100 & \multirow[t]{2}{*}{9.22} & \multirow[t]{2}{*}{0.05} \\
\hline $\begin{array}{l}\text { Bridging nursing } \\
\text { program }\end{array}$ & 10.8 & 12.3 & 33.8 & 20.0 & 23.1 & 100 & & \\
\hline Total & 8.0 & 15.2 & 40.8 & 20.8 & 15.2 & 100 & & \\
\hline
\end{tabular}

Table 5 Perceived clinical decision-making among students in baccalaureate and bridging nursing programs

\begin{tabular}{|c|c|c|c|c|c|c|}
\hline \multirow[t]{2}{*}{ Items } & \multicolumn{2}{|c|}{$\begin{array}{l}\text { Undergraduate nursing } \\
\text { program }\end{array}$} & \multicolumn{2}{|c|}{ Bridging nursing program } & \multirow[t]{2}{*}{$\begin{array}{l}\text { Student's } \\
t \text {-test }\end{array}$} & \multirow[t]{2}{*}{$p$-Value } \\
\hline & Mean & Std. deviation & Mean & Std. deviation & & \\
\hline Search for alternatives and options & 34.98 & 4.72 & 37.19 & 4.62 & -2.67 & $<0.05$ \\
\hline Canvassing of objectives and values & 37.68 & 4.80 & 40.72 & 4.41 & -3.73 & $<0.05$ \\
\hline Evaluation and reevaluation of consequences & 35.98 & 4.30 & 38.50 & 5.06 & -3.01 & $<0.05$ \\
\hline $\begin{array}{l}\text { Search for information and unbiased assimilation } \\
\text { of new information }\end{array}$ & 34.23 & 5.09 & 38.85 & 5.07 & -5.14 & $<0.05$ \\
\hline Total CDMNS & 142.83 & 15.13 & 155.25 & 14.78 & -4.69 & $<0.05$ \\
\hline
\end{tabular}

Abbreviation: CDMNS, Clinical Decision Making In Nursing Scale.

are also comparatively condensed. Students involved in nursing programs, whatever their length, usually have to spend a large amount of time learning both in and out of the classroom.

The results of the present study also showed that there is a practical statistically significant difference between the distributions of the two groups in terms of hours spent at clinical rotations per week. This difference may be attributed to the different distribution of credit hours occupied by clinical training in the baccalaureate and bridging programs, as bridging students need to complete more hours in a clinical setting to obtain the total number of hours needed for the BSN degree. Credit hour is the unit of measuring educational credit, based on the number of clinical hours per week throughout the semester. A major part of training is a large time commitment in simulation laboratories and clinical settings, and this will help the students to improve their clinical decision-making skills. ${ }^{8}$ Therefore, many students need to receive guidance in ways to balance their various commitments. It is highly important that student nurses develop and demonstrate sound clinical decision-making skills to improve the quality of care provided. ${ }^{8}$

In addition, there were statistically significant differences for all subscales and total perceived clinical decision-making on the nursing scale: students in the bridging nursing program had higher values for the mean and median compared with those in the baccalaureate program. This may be a consequence of the fact that bridging students already have significant job experience, which increases their extended learning. This may reinforce the research of Baker, ${ }^{21}$ who concluded that a major role in clinical decision-making is gained through knowledge and experience. Teng et $\mathrm{al}^{22}$ also stated that clinical decision-making is affected by the clinical experience. For instance, a nurse with clinical experience in the emergency room can competently decide that a particular patient needs to receive advanced cardiac life support or should be given emergency drugs to be revived. A nurse who lacks experience in dealing with such kind of situation still needs supervision and training to enable him/her to practice good clinical decision-making. Thus, experienced registered 
nurses are at less risk for error than less experienced or newly graduate nurses. ${ }^{23}$

These results contradict those of Bjørk and Hamilton, ${ }^{24}$ however, who found that the decision-making model used by nurses does not depend on their level of knowledge or experience, but rather on the type of task and context of the situation. Novice nurses' errors may be owing to lack of preparedness in critical-thinking skills, time management, and prioritizing patient care, and their ability to transfer theoretical training to real-work situations. ${ }^{25,26}$ Additionally, as mentioned by Yanhua and Watson, ${ }^{23}$ the lowest competencies for novice nurses are related to their abilities to make clinical decisions based on the interpretation of assessment data, to recognize any changes in patients' condition, and to provide follow-up.

\section{Relevance to Clinical Practice}

Clinical decision-making capabilities may be the most important component in the quality of patients' care. ${ }^{27}$ In this respect, nursing errors among novice nurses can be reduced through effective decision-making abilities. ${ }^{28}$

Nurse educators should focus more on clinical simulation as a teaching method because it allows nursing students to function in real-life patient situations in a safe environment and to examine patient conditions and make sound clinical decisions. Consequently, undergraduate nursing programs should be designed to develop nursing students' critical thinking and decision-making skills. When students are exposed to simulation scenarios, these conditions give them a chance to put their knowledge into practice and to develop clinical decision-making skills in a relatively safe situation. ${ }^{1}$ This kind of practice helps graduate nurses to have the confidence and creativity to transcend formal rules and standards to deliver high-quality patient care. ${ }^{29}$ Book knowledge is fine and necessary, but clinical simulation provides experience and the deep knowledge that comes from it so that students have something more than textbooks and abstract knowledge to guide them. ${ }^{29}$

If the nursing education curriculum can change from emphasizing content to promoting concepts, doing so will train nurses in critical thinking, enabling them to synthesize their information, apply their knowledge to everyday situations, and become learners for life. The obvious conclusion is that such training for nurses will have a profound positive impact on patient care.

\section{Conclusion}

Students in the bridging program have better decision-making skills compared with students in the baccalaureate program. Additionally, it can be concluded that students of the bridging program spend more hours in both class and clinical setting per week than those in the baccalaureate program, probably because the bridging program is condensed into 2 years compared with the baccalaureate program, which is 4 years. Moreover, these bridging students have previous work experience on which clinical decision skills were required.
To provide high-quality patient care, educators urgently need to develop nurses' clinical decision-making skills. Nurses in this era are faced with increasing patient acuity and complicated technology that they need to be able to manage. Nevertheless, researches have shown that new graduates face difficulties in transferring theory to practice and do not attain the skills necessary for competent clinical decision-making. ${ }^{10,30-32}$

Greater efforts and actions are needed to understand decision types and factors, which influence the decisions that students in the clinical areas make. Blending bridging and baccalaureate students in several classes as they share their experiences might help to improve baccalaureate program students' clinical decision-making skills. Doing so might help in releasing well qualified and competent graduates to the market. In addition, developing and improving nursing curricula to assure that clinical decision-making skills are integrated throughout the nursing curriculum will lead to graduating competent, autonomous decision-makers. Further, a mentoring system in which undergraduate students are paired with bridging students when they train in the clinical setting may help students learn to make sound clinical decisions.

Their ability to do so can also be improved by employing many decision-making tools such as brainstorming, critical thinking, the problem-solving process, cause-and-effect diagrams, decision trees, and the Delphi technique. ${ }^{8}$ These tools will help to assure that the decision-making process is objective and that all aspects of any problem are considered and thus will guide the processes. ${ }^{8}$

However, nurse educators should also consider that student nurses must practice in a safe environment. ${ }^{8}$ Clinical simulation provides an environment where student nurses can practice on improving patient conditions similar to those in real life without fear of harming patients. ${ }^{33}$ Doing so will help to advance nursing students' critical thinking, problem-solving, and decision-making skills, and their capability in managing patients so that they are better prepared for the clinical setting. ${ }^{8,34}$ Clinical simulation offers safe learning opportunities for nursing students to make clinical decisions. ${ }^{35}$ According to AL-Dossary, ${ }^{8}$ clinical simulation is an effective teaching method to prepare students to become skillful decision-makers.

\section{Conflict of Interest \\ None declared.}

\section{References}

1 Dang D, Dearholt SL. Johns Hopkins Nursing Evidence-Based Practice: Model and Guidelines. Indianapolis, IN: Sigma Theta Tau; 2017

2 Siew Eng H, Mohamad N, Ismail N, Zain J. Nurses' decision-making skill in the clinical nursing setting of a tertiary hospital. New Iraqi J Med 2011;7:81-87

3 Al-Dossary RN, Kitsantas P, Maddox PJ.Clinical decision-making among new graduate nurses attending residency programs in Saudi Arabia. Appl Nurs Res 2016;29:25-30 
4 Voldbjerg SL, Grønkjaer M, Wiechula R, Sørensen EE. Newly graduated nurses' use of knowledge sources in clinical decision-making: an ethnographic study. J Clin Nurs 2017;26(9-10):1313-1327

5 Tomlinson J. Using clinical supervision to improve the quality and safety of patient care: a response to Berwick and Francis. BMC Med Educ 2015;15(1):103

6 Jahanpour F, Sharif F, Salsali M, Kaveh MH, Williams LM. Clinical decision-making in senior nursing students in Iran. Int J Nurs Pract 2010;16(6):595-602

7 Thabet M, Eman E, Abood SA, Morsy SR. The effect of problem-based learning on nursing students' decision making skills and styles. J Nurs Educ Pract 2017;7(6):108-116

8 Al-Dossary RN. The Saudi Arabian 2030 vision and the nursing profession: the way forward. Int Nurs Rev 2018;65(4):484-490

9 Tiffen J, Corbridge SJ, Slimmer L. Enhancing clinical decision making: development of a contiguous definition and conceptual framework. J Prof Nurs 2014;30(5):399-405

10 Ulrich B, Krozek C, Early S, Ashlock CH, Africa LM, Carman ML. Improving retention, confidence, and competence of new graduate nurses: results from a 10-year longitudinal database. Nurs Econ 2010;28(6):363-376

11 Forber J, DiGiacomo M, Davidson P, Carter B, Jackson D. The context, influences and challenges for undergraduate nurse clinical education: continuing the dialogue. Nurse Educ Today 2015;35(11):1114-1118

12 Bourgeois S, Drayton N, Brown AM. An innovative model of supportive clinical teaching and learning for undergraduate nursing students: the cluster model. Nurse Educ Pract 2011;11(2):114-118

13 Almalki M, FitzGerald G, Clark M. The nursing profession in Saudi Arabia: an overview. Int Nurs Rev 2011;58(3):304-311

14 Institute of Medicine (US). Committee on the Robert Wood Johnson Foundation Initiative on the Future of Nursing. The Future of Nursing: Leading Change, Advancing Health. Washington, DC: National Academies Press; 2011

15 Bashatah A, Alkorashy H. Challenges in curriculum designs: RN to BSN bridging program at King Saud University. Paper given at Business and Health Administration Association, Division of MBAA International Meeting, Chicago, Illinois, March 2011

16 Alamri M. Higher education in Saudi Arabia. J Higher Educ Theory Pract 2011;11(4):88-91

17 Kriston L, Scholl I, Hölzel L, Simon D, Loh A, Härter M. The 9-item Shared Decision Making Questionnaire (SDM-Q-9). Development and psychometric properties in a primary care sample. Patient Educ Couns 2010;80(1):94-99

18 Thomas C, Mackey E. Influence of a clinical simulation elective on baccalaureate nursing student clinical confidence. J Nurs Educ 2012;51(4):236-239

19 Thompson C, Aitken L, Doran D, Dowding D. An agenda for clinical decision making and judgement in nursing research and education. Int J Nurs Stud 2013;50(12):1720-1726
20 Waltz CF, Strickland OL, Lenz ER, Eds. Measurement in Nursing and Health Research. New York, NY: Springer; 2010 Apr 17

21 Baker JD. Nurses' perceptions of clinical decision making in relation to patients in pain. http://hdl.handle.net/2123/489. Accessed November 4, 2019

22 Teng CI, Shyu YI, Chiou WK, Fan HC, Lam SM. Interactive effects of nurse-experienced time pressure and burnout on patient safety: a cross-sectional survey. Int J Nurs Stud 2010;47(11):1442-1450

23 Yanhua C, Watson R. A review of clinical competence assessment in nursing. Nurse Educ Today 2011;31(8):832-836

24 Bjørk IT, Hamilton GA. Clinical decision making of nurses working in hospital settings. Nurs Res Pract 2011;2011:524918

25 Sedgwick M, Harris S. A critique of the undergraduate nursing preceptorship model. Nurs Res Pract 2012;2012:248356, $10.1155 / 2012 / 248356$

26 Morrow S. New graduate transitions: leaving the nest, joining the flight. J Nurs Manag 2009;17(3):278-287

27 Dorgham SR, Al-Mahmoud SA. Leadership styles and clinical decision making autonomy among critical care nurses: a comparative study. IOSR J Nurs Health Sci 2013;1(4):71-83

28 Gillespie M, Peterson BL. Helping novice nurses make effective clinical decisions: the situated clinical decision-making framework. Nurs Educ Perspect 2009;30(3):164-170

29 Van Graan AC, Williams MJ, Koen MP. Professional nurses' understanding of clinical judgement: a contextual inquiry. Health SA Gesondheid 2016;21(1):280-293

30 Griffiths P, Jones S, Bottle A. Is "failure to rescue" derived from administrative data in England a nurse sensitive patient safety indicator for surgical care? Observational study. Int J Nurs Stud 2013;50(2):292-300

31 Kavanagh JM, Szweda C. A crisis in competency: the strategic and ethical imperative to assessing new graduate nurses' clinical reasoning. Nurs Educ Perspect 2017;38(2):57-62

32 AL-Dossary R. Clinical Decision Making in the Nursing Profession, A Guide for Nursing Students. Beau Bassin, Mauritius: Lambert Academic; 2018

33 Groves PS, Bunch JL, Cram E, Perkhounkova Y. Development and feasibility testing of a patient safety research simulation. Clin Simul Nurs 2018;15:27-33

34 Arslan FT, Türkmen AS, Çelen R, Özkan S, Altıparmak D, Şahin A. Comparing traditional and simulation-based experiences in pediatrics with undergraduate nursing students in Turkey. Clin Simul Nurs 2018;16:62-69

35 National League for Nursing (NLN) Board of Governors. A vision for teaching with simulation: a living document from the National League for Nursing. 2015. http://www.nln.org/docs/ default-source/about/nln-vision-series-(position-statements)/ vision-statement-a-vision-for-teaching-with-simulation. pdf?sfvrsn=2. Accessed January 8, 2019 